\title{
Liposuction Assisted Brachioplasty: Posterior Scar Technique Versus Medial Scar Technique
}

\author{
HAMED S. ABOKHADRA, M.Sc.; TAREK G. SHOUKR, Ph.D.; WALID A. MOSTAFA, Ph.D. and \\ NADER G. EL-MELEGY, M.B.C.H.B., Ph.D.
}

The Department of Plastic and Reconstructive Surgery, Faculty of Medicine, Tanta University, Tanta, Egypt

\begin{abstract}
Background: Massive weight loss generates body deformities. Therefore, the demand for body contouring surgery is increasing steadily. The aim of this study is to evaluate the use of liposuction-assisted brachioplasty technique in achieving better arm contouring and to describe the complications and patient satisfaction through the analysis of functional and aesthetic criteria of medial scar versus posterior scar brachioplasty.

Methods: A total of 14 patients were recruited during 2015 at Tanta University Hospital and were randomized into 2 groups Group A: (7 patients) underwent medial scar technique and Group B: (7 patients) underwent posterior scar technique.

Results: The study included 14 female patients in which the posterior scar technique had an average operative time of 90 minutes which is shorter than medial scar technique which had an average operative time of 118 minutes with lower complication rate with posterior scar technique but more arm reduction with medial scar technique.

Conclusion: Brachioplasty operation is a good method to treat patients with arm obesity or post massive weight loss skin ptosis. Medial scar technique showed significant more reduction in arm circumference than posterior scar technique. However posterior scar technique demonstrated significantly shorter operative time, better scar quality and more patient satisfaction with less incidence of complications than medial scar technique.
\end{abstract}

Key Words: Liposuction - Assisted brachioplasty.

\section{INTRODUCTION}

The incidence of obesity is rising worldwide and represents a growing global health concern. Accordingly, the massive weight loss population is increasing either through bariatric surgery or lifestyle changes and dietary modifications. Massive weight loss generates body deformities. Therefore, the demand for body contouring surgery is increasing steadily [1]. Brachioplasty was first described by Correa-Iturraspe and Fernandez [2].

A variety of useful methods for arm rejuvenation are now available. Unfortunately, none of these methods has provided full satisfaction. Among these methods are dermolipectomy of the arm with the scar oriented longitudinally and placed in the brachial sulcus [3], W-plasties [4], quadrangular flaps and $\mathrm{T}$ closure [5], the deepithelialized rolledup flap [6], fascial system suspensions [7], and lipoaspiration [8], Liposuction-Assisted Medial Brachioplasty [9], Liposuction-Assisted Posterior Brachioplasty [10].

The focus of the modifications has mainly been to improve the poor aesthetic result of scar sequelae, such as retractility, healing, and widening of the scar [11].

\section{PATIENTS AND METHODS}

A total of 14 patients were recruited in the period between January 2015 and December 2015 at Tanta University Hospital in the Department of Plastic and Reconstructive Surgery. Two techniques were used for brachioplasty; liposuction assisted medial scar brachioplasty and liposuction assisted scar posterior brachioplasty. Patients were randomized into 2 groups:

Group A (7 patients): Underwent medial scar technique and Group B (7 patients): Underwent posterior scar technique.

We included patients suffering from brachialptosis including excess arm skin and adipose tissue. While patients with unrealistic expectations, body dysmorphic disorders, eating disorders, uncontrolled chronic medical comorbidities especially respiratory as (COPD) were excluded. Informed consent was taken from all patients and the patients were identified by a code number to maintain confidentiality.

\section{Preoperative marking:}

Precise preoperative markings were drawn the day before surgery, with the patient standing and with arms raised and abducted 90 degrees, and forearms supinated. 


\section{Marking for medial scar brachioplasty:}

The first mark was a straight horizontal line below the medial intermuscular groove, which corresponded to the location of the future scar. Downward traction was applied to pull the upper skin to the first line, and then the upper line was drawn. A pinch test was executed to evaluate the redundant skin and to draw the lower line. The pattern of incision was elliptical, with a proximal limit near the axillary dome and a distal limit just after the distal end of the excessive skin tissue (often near the medial epicondyle).

\section{Marking for posterior scar brachioplasty:}

The posterior landmark was marked midway between the olecranon and the medial epicondyle and extended to the axilla. The anterior landmark was placed 1 finger breadth below the brachial sulcus and met the posterior landmark on both ends.

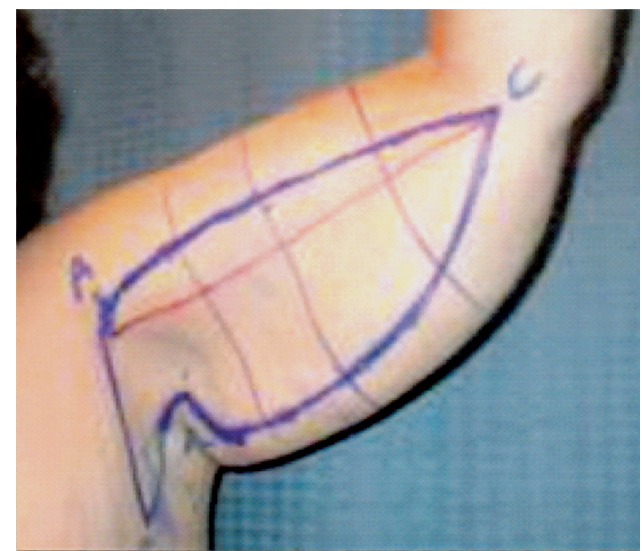

Fig. (1): Shows marking for medial scar brachioplasty.

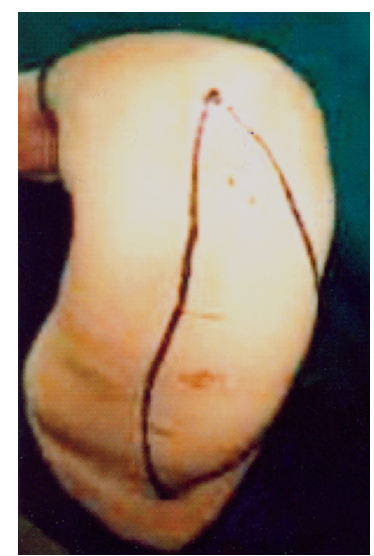

Fig. (2): Shows marking for posterior scar.

\section{Surgical procedure:}

The patient was first placed in the supine position, with arms abducted to 90 degrees.

Two grams of $3^{\text {rd }}$ generation ecphalosporins were infused intravenously before the incision.
The upper limbs and lateral chest wall were prepared and included in the operating field. The liposuction areas, including the resection area and the incision lines were infiltrated with 1 liter of normal saline solution containing $1 \mathrm{mg}$ of epinephrine. To avoid additional scars, liposuction access points were placed in the resected area.

Liposuction was performed with a 4-mm cannula. The entire superficial fat compartment between the skin and the medial arm's aponeurosis was removed in the expected area of skin. The aesthetic aspect was checked (i.e., scar placement, symmetry) and, if necessary, drawn lines were modified. Additional markings were made perpendicular to the incision, to facilitate the final closure. The incision was made just below the subdermal plane. Continuous traction was maintained on the skin to ease the resection.

Only the skin layer was resected, preserving the lattice of subcutaneous vessels and lymphatics and avoiding bleeding. Incisions were closed in a three-layer fashion. The subcutaneous and dermal planes were first closed with inverted interrupted absorbable 2-0 and 3-0 sutures. This closed any dead spaces. An absorbable 3-0 subcuticular running suture was then used to close the skin layer. A dressing was applied, and followed immediately by a compression garment.

\section{Parameters of comparison:}

Reduction in arm circumference: Measured by the measuring tape.

Scar quality scale.

Table (1): The Stony Brook Scar Evaluation Scale [12].

\begin{tabular}{lc}
\hline Scar category & Point \\
\hline Width: & \\
$\quad$ Scar widening prominent, width $>2 \mathrm{~mm}$ & 0 \\
Scar widening present, width $\leq 2 \mathrm{~mm}$ & 1 \\
$\quad$ No scar widening & 2 \\
Height: & \\
$\quad$ Prominent scar elevation & 0 \\
Scar elevation present & 1 \\
$\quad$ No scar elevation & 2 \\
Color (redness): & \\
$\quad$ Scar prominently more red than the surrounding & 0 \\
$\quad$ skin & \\
Scar more red than the surrounding skin & 1 \\
Scar of the same color or lighter than surrounding & 2 \\
$\quad$ skin & \\
Incision line: & \\
Prominent incision line & \\
Incision line present & \\
Incision line absent &
\end{tabular}


Scores are added together to give an overall score for the scar, where the higher scores representing clinically good scars and the lower scores representing clinically worse scars.

Incidence and types of complications: Multiple complications to be assessed such as wound dehiscence, hypertrophic scar, temporary numbness of skin of medial aspect of the arm and seroma.

Patient satisfaction: Analysis of the data according to the Likert Scale [13].

A Likert scale and an evaluation questionnaire were used to assess the aesthetic outcome of the both techniques. Patients were rated on a 5-point Likert scale with 1 (very dissatisfied), 2 (dissatisfied), 3 (moderately satisfied), 4 (satisfied), and 5 (very satisfied). Multiple dimensions were used to analyze patient's satisfaction, satisfaction with location of the scar, symmetry of the scar, quality of the scar, arm contouring and satisfaction with the aesthetic outcome.

\section{RESULTS}

All the patients were females. There was no significant difference between mean values of patient ages of the two groups with Group A mean of 42 and Group B mean of 44. The posterior scar technique had an average operative time of 90 minutes which is shorter than medial scar technique which had an average operative time of 118 minutes.
Incidence and types of complications: From the data described in Table (2) we found that the incidence and types of complications in Group A were more than that in Group B.

Arm circumference: The mean arm circumference preoperatively in group A was $49.42 \mathrm{~cm}$ and in group B was $49.28 \mathrm{~cm}$. Reduction in the arm circumference was found to be more in medial scar technique than in Posterior scar technique and this reduction was statistically significant as group A had a mean of $37.28 \mathrm{~cm}$ with an average $\%$ of arm circumference reduction equal to $24.47 \%$ while group B had a mean of $39.14 \mathrm{~cm}$ with an average\% of arm circumference reduction equal to $20.64 \%$. We believe that medial markings and dissection from the medial aspect of the arm allows more excess skin and soft tissue to be excised.

Table (2): Complications.

\begin{tabular}{|c|c|c|c|c|}
\hline \multirow[t]{2}{*}{ Technique } & \multicolumn{2}{|c|}{$\begin{array}{l}\text { Group A } \\
\text { medial scar } \\
\text { technique }\end{array}$} & \multicolumn{2}{|c|}{$\begin{array}{l}\text { Group B } \\
\text { posterior scar } \\
\text { technique }\end{array}$} \\
\hline & $\begin{array}{l}\text { No. of } \\
\text { arms }\end{array}$ & $\begin{array}{l}\text { Percent } \\
(\%)\end{array}$ & $\begin{array}{l}\text { No. of } \\
\text { arms }\end{array}$ & $\begin{array}{c}\text { Percent } \\
(\%)\end{array}$ \\
\hline \multicolumn{5}{|l|}{ Complication: } \\
\hline Mild wound dehiscence & 1 & 7.14 & 1 & 7.14 \\
\hline Hypertrophic scar & 6 & 42.85 & 3 & 21.42 \\
\hline $\begin{array}{l}\text { Temporary numbness of } \\
\text { skin of medial aspect } \\
\text { of the arm }\end{array}$ & f 2 & 14.28 & 1 & 7.14 \\
\hline Seroma & 1 & 7.14 & 1 & 7.14 \\
\hline
\end{tabular}
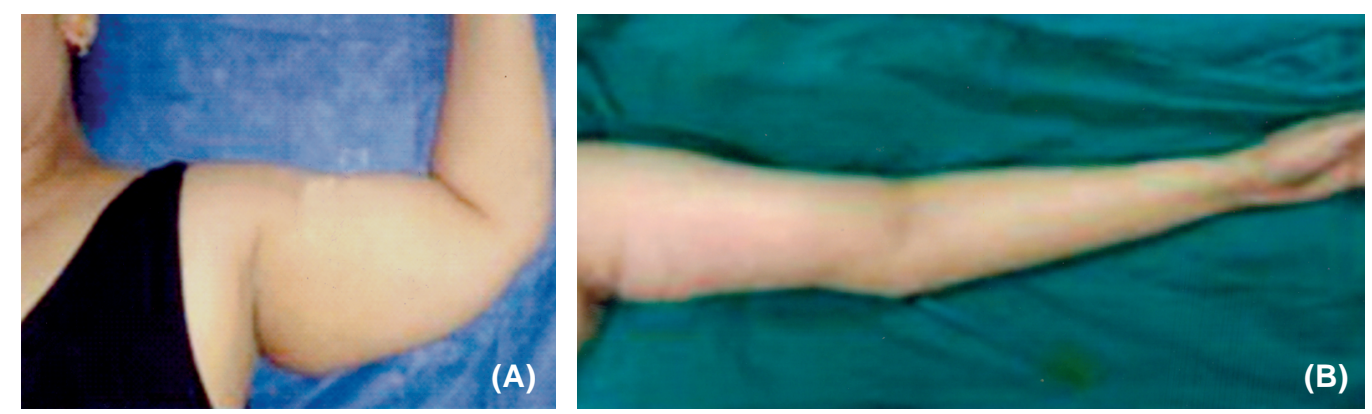

Fig. (3): A case of medial scar brachioplasty, preoperative and immediate post-operative, shows great reduction of arm circumference.
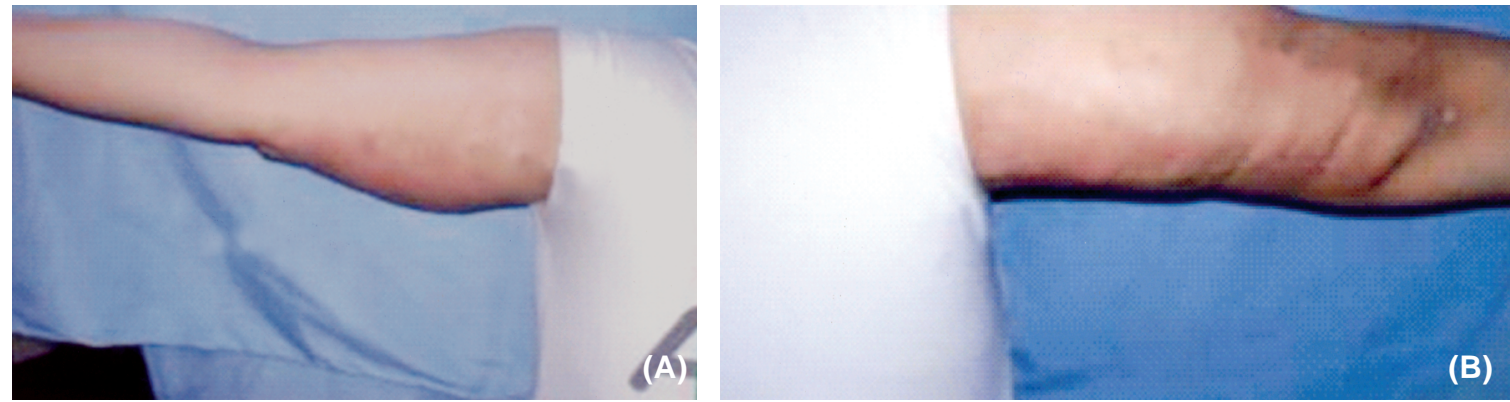

Fig. (4): A case of posterior scar brachioplasty follow-up after 4 months with excellent scar appearing from behind with full patient satisfaction. 
Scar quality: According to The Stony Brook Scar Evaluation Scale the scar quality of both techniques were noticed with a significant difference between mean values of Scar quality scale of posterior (mean of 5\%) and Medial (mean of 3.5\%) scare technique for the benefit of posterior technique.

Patient's satisfaction: Patient's satisfaction was found to be more in posterior scar technique than in medial scar technique.

Table (3): Patients' satisfaction.

\begin{tabular}{|c|c|c|c|c|}
\hline & Dissatisfied & Moderately satisfied & Satisfied & Very satisfied \\
\hline Arm contouring & & & & $\begin{array}{l}\text { All the } 14 \text { patients in } \\
\text { Group A\&B } 100 \%\end{array}$ \\
\hline Location of the scar & & 12 arms in Group A $85.71 \%$ & $\begin{array}{l}2 \text { arms in Group A } 14.28 \% \\
4 \text { arms in Group B } 28.57 \%\end{array}$ & 10 arms in Group B $71.42 \%$ \\
\hline Symmetry of the scar & & & & $\begin{array}{l}\text { All the } 14 \text { patients in } \\
\text { Group A\&B } 100 \%\end{array}$ \\
\hline Quality of the scar & & 12 arms in Group A $85.71 \%$ & $\begin{array}{l}2 \text { arms in Group A } 14.28 \% \\
4 \text { arms in Group B } 28.57\end{array}$ & 10 arms in Group B $71.42 \%$ \\
\hline Aesthetic outcome & & 6 arms in Group A $42.85 \%$ & $\begin{array}{l}8 \text { arms in Group A } 57.41 \% \\
8 \text { arms in Group B } 57.41 \%\end{array}$ & 6 arms in Group B $42.85 \%$ \\
\hline
\end{tabular}

\section{DISCUSSION}

Through the years, thanks to newer technologies and techniques, brachioplasty has evolved into a useful item in the cosmetic surgeon's armamentarium. Pleasing results can be obtained with fewer complications than previously experienced, provided that the surgeon has assessed the patient completely and has a good working knowledge of all the various treatment options now available [14].

Salem et al., reported that still the major side effect or patient complaint described in association with brachioplasty is the resultant scar. Unfortunately, this procedure can lead to widened, unsightly scars that may be constantly noticed in a patient's daily life. There has been an ongoing debate in the brachioplasty literature regarding the optimum placement of these scars. Some have advocated for a medially based scar in the bicipital groove. Others advocate a posterior scar in the brachial sulcus. One author writes that the position of the scar "is a matter of taste and philosophy" [15].

In our study, it was found that the mean operative time in posterior scare technique (90min) was shorter than that in medial scare technique (118min).

We believe that the posterior scar technique is much easier in markings with straight forward operative steps. We believe that the higher patient satisfaction with posterior scar group in our study may be due to that the patient cannot see his scar easily.
There is commonly debated concept regarding scar placement posteriorly versus medially. A medial scar lies in less visible area (only seen when the arm is externally rotated and abducted); however, the poor dermal quality of the skin here creates an often-wider scar. A posterior scar can be a fine-line scar because of better dermal quality, but this will be visible from behind when the patient wears sleeveless clothing [16].

\section{Conclusion:}

Even to this day, brachioplasty continues to be a cosmetic challenge to the plastic surgeon. A compromise must often be made between the presence of scars and the aesthetic desires of the patient. Brachioplasty operation whether liposuction assisted Medial scar brachioplasty or Posterior scar brachioplasty is a good method to treat patients with arm obesity or post massive weight loss skin ptosis. The overall procedures were tolerated well by the patients with acceptable complications. Medial scare technique showed significant more reduction in arm circumference than posterior scare technique. However, posterior scare technique demonstrated significantly shorter operative time, better scar quality and more patient satisfaction with less incidence of complications than Medial scare technique.

\section{REFERENCES}

1- Fischer J.P., et al.: Complications in body contouring procedures: An analysis of 1,797 patients from the 20062010 ACS-NSQIP databases. Plast. Reconstr. Surg., 132: 1411-1420, 2013. 
2- Correa-Iturraspe M. and Fernandez J.C.: Dermatolipectomia braquial. Prensa Med. Argent., 41: 2432, 1954.

3- Baroudi R.: Dermolipectomy of the upper arm. Clin. Plast. Surg., 2: 485-489, 1975.

4- Borges A.F.: W-plastic dermolipectomy to conect batwing deformity. Ann. Plast. Surg., 9: 498-501, 1982.

5- Juri J., Juri C. and Elias J.C.: Arm dernolipectomy with a quadrangular flap and "T" closure. Plast. Reconstr. Surg., 64: 521-525, 1979.

6- Goddio A.S.: A new technique for brachioplasty. Plast. Reconstr. Surg., 84: 85-91, 1989.

7- Lockwood T.: Brachioplasty with superficial fascial system suspension. Plast. Reconstr. Surg., 96: 912-920, 1995.

8- Lillis P.J.: Liposuction of the arms. Dermatol. Clin., 17: 783-797, 1999

9- Runz A., Colson T. and Minetti C.: Liposuction-assisted medial brachioplasty after massive weight loss: An efficient procedure with a high functional benefit. Plast. Reconstr. Surg., 135: 74-84, 2015.
10- Nguyen A.T. and Rohrich R.J.: Liposuction-assisted posterior brachioplasty: Techical refinements in upper arm contouring. Plast. Reconstr. Surg., 126 (4): 1365-9, 2010 .

11- El-Khatib H.A.: Posterior scar brachioplasty with fascial suspension: A long-term follow-up of a modified technique. Plast. Reconstr. Surg. Glob Open, 1: e38, 2013.

12- Singer A.J., Arora B., Dagum A., et al.: Development and validation of a novel scar evaluation scale. Plast. Reconstr. Surg., 120 (7): 1892-7, 2007.

13- Sitzia J.: How valid and reliable are patient satisfaction data? An analysis of 195 studies. Int. J. Qual Healthcare, 11 (4): 319-328, 1999.

14- A.C. Sacks: Brachioplasty: How to choose the correct procedure, Springer-Verlag Berlin Heidelberg, 2010.

15- Salem Samra, et al.: Optimal placement of a brachioplasty scar a survey evaluation. Ann. Plast. Surg., 71: 329Y332, 2013.

16- Janis J.E.: Essentials of plastic surgery $2^{\text {nd }}$ edition, Chapter 99, p. 1260-1261, 2014 